\title{
Dictionary' Use among Second Year Students of English at the University of Constantine 1
}

Received: 27/02/2017 ; Accepted: 10/02/2019

\section{Abstract}

Despite the dynamic growth of research into dictionary use, we are still far from getting definitive answers to many important questions regarding dictionary use. We still do not know much about how dictionaries are perceived and used by students. We are also ignorant of the problems students encounter while using them. So, this paper seeks to gather information about dictionary use among second year students of English at the University of Constantine 1 . The results of the study revealed that the dictionary is an elementary tool for learners. The Participants use different types of dictionaries in particular monolingual electronic ones. However, they lack the skills to use their dictionaries effectively because most of them have not received any instruction on dictionary use. Teachers, therefore, have to equip students with the necessary reference skills, which in turn will have a positive influence on students 'dictionary use.

Keywords: dictionary, reference needs reference skills.
Amina Ouafa

\section{BENZITOUNI*}

MCB Larbi Ben M'hidi university Algeria

\section{Résumé}

Malgré la croissance dynamique de la recherche sur l'utilisation du dictionnaire, nous sommes encore loin d'avoir des réponses définitives à de nombreuses questions importantes concernant l'utilisation du dictionnaire. Nous ne savons toujours pas grand chose sur la façon dont les dictionnaires sont perçus et utilisés par les étudiants. Cet article cherche donc à recueillir des informations sur l'utilisation du dictionnaire par les étudiants de deuxième année d'anglais de l'Université de Constantine 1. Les résultats de l'étude ont révélé que le dictionnaire était un outil élémentaire pour les étudiants. Les participants utilisent différents types de dictionnaires. Cependant, ils n'ont pas les compétences nécessaires pour utiliser leurs dictionnaires de manière efficace, car la plupart d'entre eux n'ont reçu aucune instruction sur leur utilisation. Les enseignants doivent donc doter les étudiants des compétences de référence nécessaires, qui auront à leur tour une influence positive sur l'utilisation du dictionnaire par les étudiants.

Mots clés: dictionnaire, référence nécessite des compétences de référence

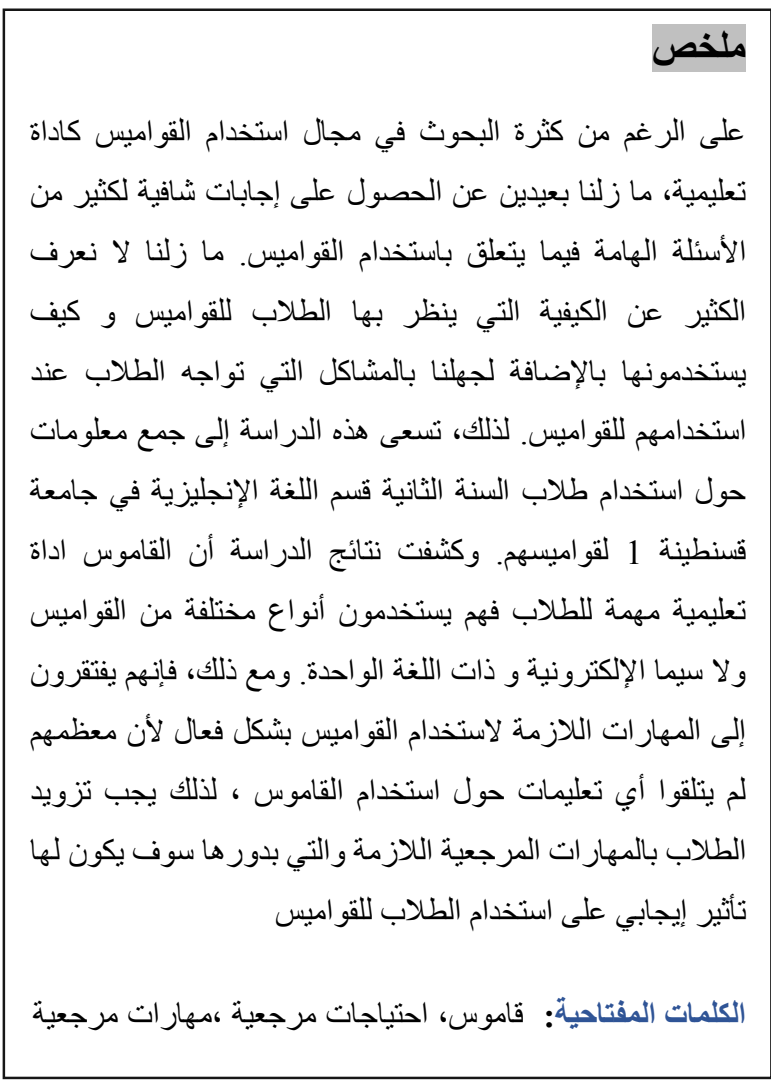

\footnotetext{
* Corresponding author, e-mail: amnwben@gmail.com
} 


\section{I- Introduction :}

The Dictionaries have always been considered an essential tool in the process of language learning. However, recently several learners' dictionaries have become widely spread. Since the introduction of corpus-based lexicography in 1980, dictionary making knew deep changes and became very vigorous and competitive. Publishers have shifted focus from the dictionaries to the users. Users' reference skills and needs in using dictionaries became badly taken into account and the new learners' dictionaries included many innovations which are claimed to be user-oriented, such as defining vocabulary and indications of word frequency (Rundell, 1999). It was "clear that these products have proved highly responsive in both design and content to the needs and demands of their users, and have consequently improved much faster and more comprehensively than any other type of dictionary" (ibid, p.42).

The notion of "user perspective" was first used by Zgusta (1971). He puts forward that dictionary-makers are supposed to design dictionaries intended for a specific type of users, taking into account their specific needs and reference skills, i.e. with regards to the type and place of the users, plus the problems they may come across when using the dictionary (ibid).That is why, research is considered necessary to discover the purpose and kinds of dictionaries students use and find out the complications that hamper their effective use of dictionaries (Hulstijn \& Atkins, 1998).

So, the aim of this paper is to know how a group of second year students of English at the University of Constantine Algeria use their dictionaries. Specifically, we aim to:

1. Identify which type of dictionaries students use most.

2. Find out if students benefit from all the information provided in their monolingual dictionaries.

3. Look at the problems students face while using their dictionaries and whether the students are trained on how to use their dictionaries effectively.

\section{II -Literature Review:}

The dictionary is considered one of the antique and popular books in literate societies (Kirkness, 2004). Dictionaries of various sorts for various reasons are produced (Béjoint, 2000). Many researchers have tried to categorize dictionary types, but the task was not viable (Hartmann, 2001). Swanepoel (2003) assumes that dictionaries can be classified into different kinds on the basis of users needs since new demands lead to the creation of new types of dictionaries.

\section{Monolingual, Bilingual, and Bilingualised Dictionaries:}

Using either monolingual dictionary or bilingual dictionary has always been a subject of controversy among researchers. Teachers and learners have different views for the different types of dictionaries; while students like electronic bilinguals for immediate satisfaction and rapidity, teachers prefer paper monolinguals for long-term benefits (Koren, 1997).

Although bilingual dictionaries are not designed for learners, they become learners' dictionaries by the force of practice. The majority of advanced learners own and consult bilingual rather than monolingual dictionaries (Baxter, 1980).

According to Nation (2001) bilingual dictionaries are useful for understanding meaning easily: they can be used when writing or speaking in the target language whereas a vocabulary of at least 2,000 words is needed to understand the definitions when using a monolingual dictionary. In addition, the helpful information existing in the front and back of the bilingual dictionary is better understood because it is usually in the learners' native language. 
However, Cowie (1999, p. 184) mentions that some learners prefer to use monolingual dictionaries, even they do not find them helpful, to imitate their teachers who generally consult monolingual dictionaries. Accordingly, "a wide gap often exists between a student's perception of the dictionary's value and its actual usefulness as an aid to learning".

Nation (2001) maintains that bilingual dictionaries have been disapproved of as they encourage translation, foster one-to-one word correspondence between two languages, and provide little information on words usage. Similarly, Schmitt \& McCarthy (1997) stress that bilingual dictionaries are misleading since languages often do not have direct equivalents.

The monolingual dictionary is a helpful learning resource for the EFL learners if used properly. Being in a non-native environment, unawareness and confusions about the right meaning, pronunciation, stress and how to use words in context are very frequent. As EFL learners cannot at all times ask their teachers on all these aspects of word knowledge they wish to learn, monolingual dictionaries can help (Nation, 2001).

Another choice available besides monolingual and bilingual dictionaries is the semi-bilingual dictionary, known as the hybrid or bilingualized dictionary. Bilingualized dictionaries provide learners with L2 definitions and L1 translation, in the case of looking up words in L2; and only the translation plus production information in the case of looking up words in L1 (Pujol et al, 2006).

This grouping of L2 definitions and L1 equivalents is claimed to be the advantage of bilingualized dictionaries. Bilingualized dictionaries incorporate the positive features of both monolingual and bilingual dictionaries. Learners using bilingualized dictionaries can engross in the foreign language, along with support from their native language. In this way, they are encouraged to read words explanations in the foreign language, while the translation provides a psychological reassurance that supports understanding and avoids confusion. Then by time, learners steadily learn to operate in L2 without the L1 barrier (Laufer, 1995). Unlike bilingual dictionaries, hybrid dictionaries provide only a few translations in each entry in addition to the accurate meaning and usage of the word in L2. Therefore, full understanding is achieved (Koren, 1997).

\section{The Electronic Dictionary Era:}

In recent times, a new type of dictionaries emerged which is the electronic dictionary. An electronic dictionary is "Any material reference memorized in electronic form which gives information on the spelling, the sense and the use of words." (Nesi, 2000, p. 839). Unlike paper dictionaries, electronic ones are found in CD ROMS, handheld devices and cell phones (Nesi, 1999).

Though many studies claim that the paper dictionary is a useful tool for learners who find the list of lexical items of a language put in an alphabetical order with information about spelling, pronunciation, grammar, and meaning in plain language and with example sentences that show how the words are used in practice, other studies identified a general unwillingness to consult the reference book at all, too (Strevens, 1987). For example, many learners find the paper dictionaries troublesome, demanding a lot of time in the process of word search (Nesi, 2000) which reflected doubts about learners' ability to cope successfully with their dictionaries.

With studies showing how unskilled and uninformed learners are in using their paper dictionaries, lexicographers produced electronic dictionaries. Many electronic dictionaries are now available in a variety of formats: hand-held pocket dictionaries, CD-ROM dictionaries, and Internet or online dictionaries and even cell-phone 
dictionaries. They are all prided on being innovative, learner-friendly and giving learners' information on most current English (Nesi, 1999).

One explanation for the shift from the paper dictionary to the electronic dictionary is the fact that the electronic dictionary is more capacious. Concerning the storage space i.e. the space needed for storing words and their meanings, there are no limits in electronic dictionaries, whereas, the storage space in paper dictionaries is determined by the number of volumes, layout, weight, and several other factors. Another advantage of electronic dictionaries is that they permit users to make cross references without leaving the page that the user is viewing. This characteristic of instant cross reference is absent in paper dictionaries (Lew, 2007, p. 344).

In addition, the electronic dictionary has further features which make it popular and appealing than the paper dictionary. A perceptible advantage of the electronic dictionary over is the easiness and simplicity of use whereas, it takes a lot of time and training to develop printed dictionary' reference skills. For example, one study of international students in England found that in every fifth attempt half of the learners who used paper dictionaries were unsuccessful to find dictionary entries (Nesi \& Haill 2002).

The electronic dictionary also provides other new options. For instance, the ability of actually hearing words rather than interpreting complex phonetic transcriptions which is good solution to pronunciation problems. Moreover, several recent electronic dictionaries are hybrids, including features of encyclopaedias, pedagogic grammars and teaching materials (ibid).

The traditional paper dictionary is still extensively used. They are unproblematic and easy to use. Everything you need is good vision, familiarity with the alphabetical order, and knowledge of the organization of sub-entries and information under the dictionary entry. Additionally, the nature of a printed dictionary imposes a slow browsing speed. Finding anything in a printed dictionary demands a lengthy process. In such a way, information is absorbed. Lastly, the fact of reading a book is a good academic experience (Hartmann, 1999).

\section{Different Dictionaries for Different Learners:}

Different learners prefer to use different types of dictionaries. In their study, Atkins \& Varantola (1997) state that the percentage of learners preferring bilingual dictionaries decreased with proficiency, from $88 \%$ for low proficiency students to $60 \%$ for high proficiency students. With a growing competence in the second language, learners increasingly turn to monolingual dictionaries because they turn to use dictionaries for decoding purposes. Likewise, high-proficiency students investigated by Neubach \& Cohen (1988) prefer monolingual dictionaries for their more precise meanings of words.

Cowie (1999) states that learners' skills get better with the increasing proficiency and that "among the most sophisticated language users, constant movement from one reference resource to another is the rule rather than the exception" (p.187). Moreover, a study by Laufer \& Hadar (1997) indicates that pre-advanced learners prefer using bilingual dictionaries in both comprehension and production, as opposed to advanced learners who prefer using monolingual dictionaries.

Concerning the relationship between the frequency of dictionary consultation and learners, the findings are opposing. Wingate (2002), for example, notices that dictionary use frequency increased with level. Similarly, Jakubowski (2001) finds the frequency of use to be higher for students of higher proficiency level. Other studies, however, revealed a reverse tendency, with lower proficiency users tending to use their 
dictionaries more frequently. Tomaszczyk (1987) observes learners reluctance to use dictionaries at all and report that many successful language learners in his study had never used any dictionaries

Learners' interests in the different types of information also tend to differ with their proficiency level, with the proficient users using most of the dictionary information more than the less proficient students in particular definitions, pronunciation, frequency, and appropriateness and regarded them as helpful (Fan, 2003).

\section{The Information Searched For:}

The outstanding similarity regarding the results of studies of information categories consulted in dictionaries was the preference for semantic information (summers, 1988). "the dictionary user's overwhelming preoccupation with meaning" (Cowie, 1999,p.181) was proved by many studies that found word meaning to be the information category often searched by learners as (Hartmann 1999).

The greatest part of learners "still have a perception of the dictionary [...] which is far from "instrumental", treating it as 'a storehouse of meanings rather than a resource for developing [language] activities" (Marello, cited in Cowie 1999, p. 182).

Although the largest part of EFL learners consult definitions mostly, these definitions frequently fall short of the learners' expectations. Heuberger argues that "from the various information categories presented in a learners' dictionary, definitions are certainly among the most unsatisfactory and disputable ones" (2000, p. 16).

Aside from the indisputable ascendancy of semantic information, it is difficult to order the other types of information, spelling is an exception as it is automatically provided in dictionary entries and hence frequently consulted, as gathering such data is complicated and difficult. For example, synonyms and antonyms received $72 \%$ in (Quirk, 1974) study and only 14\% in (Greenbaum, Meyer \& Taylor, 1984) study which was a replication of Quirk study (Lew, 2002).

Moreover, most learners do not consult the introductory pages in dictionaries and, hence cannot competently extract all the information given in the dictionary as illustrated by cowie (1981):

It seemed to us that monolingual dictionaries are not used as fully as they should be; their introductions are not commonly referred to and neither are the coding systems for syntactic patterns. Certainly many students are not aware of the riches that their monolingual dictionaries contain (p. 125).

So, the most important research findings on users' needs is that EFL learners use the dictionaries, primarily, for decoding purposes, with meanings being the most sought after information category followed by other categories ranking differently in various research studies. However, it needs to be highlighted that the need for a specific type of information depends on many criteria as the user, the task the dictionary is used for, and the type of dictionary used.

\section{Students Difficulties in Using Dictionaries:}

EFL learners face many problems when using dictionaries. These problems are generally divided into two categories: subjective problems which learners recognize and can report (e.g. not finding an entry), and objective problems which learners are ignorant of and it is researchers and teachers who can recognize (e.g. misunderstanding the entry). 


\section{a. Subjective Problems:}

The most prominent problem usually reported by EFL learners is word missing. The quality and comprehensibility of the definitions and pronunciation information are also frequent problems. Other infrequently reported problems include insufficient syntactic information, too extended entries, and alphabetical-order problems (Neubach \& Cohen 1988). The most difficult words to find are slang words, technical terms, multiword items, inflected words, compound nouns, idiomatic phrases, and past participles of verbs (Papanikolaou, 2003).

Winkler (2001) argues that learners problems with electronic dictionaries are similar to their problems with paper ones like extended entries, and unclear abbreviations and symbols. Winkler investigated the problems EFL learners face while using an Oxford Advanced Learner's Dictionary, Fifth Edition, in a printed and electronic form (CD-ROM through a writing task. The results showed that the problems the students face were mainly due to inadequate dictionary-using skills. Other participants were also ignorant of the information that can generally be found in an English learner's dictionary in particular in front pages and the appendices. Students had also difficulties with the structure of individual entries and checking long entries.

\section{b. Objective Problems:}

Hardly any studies revealed other problems learners themselves were ignorant of. Problems often noticed by researchers were learners not finishing up with the accurate meaning for an unfamiliar word (Nesi \& Meara, 1994). Tono (1984) states that not being able to understand an explanation is not half as bad as misunderstanding an explanation. He found that users concentrate mainly on the beginning of entries, ignoring later sub-senses and discovered that too many examples can discourage the user from reading the entire entry.

Nesi \& Haill (2002) examine the difficulties their participants faced when looking up words in the dictionary. Their participants in the study were requested to describe the way they consulted their dictionaries based on 89 assignments given to them over a period of three years. They distinguish four categories of dictionary use problems which are overlooked by the learners:

$>$ choice of the wrong entry or sub-entry

$>$ choice of the correct entry or sub-entry, but misinterpretation of the information it contained

$>$ choice of the correct entry or sub-entry, but failure to realise that the word had a slightly different (figurative) meaning in the context

$>$ The correct dictionary entry or sub-entry rejected as inappropriate in context.

Garcia (2006) blames learners for these problems and argues that they are the result of wrong dictionary use or lack of skills, rather than drawbacks of the dictionaries themselves. So, he insisted on the importance of teaching dictionary skills.

\section{Skills Needed for Effective Dictionary Use: Reference Skills:}

Wiegand (1985 cited in Tarp 2009) differentiates between three types of users: the potential user who meets the requirements for becoming a user, the well-informed user 
who is able to use a certain dictionary, and the learned user who has some notions of lexicography and knows in which dictionary type the information can be found.

According to Wright (1998), learning from dictionaries requires considerable sophistication. Learners face many difficulties when using their dictionaries. Knowing the ordering of the alphabet is insufficient for those who desire to benefit completely from what is available in dictionaries (Tickoo, 1989).

Scholfield (1997) also mentions that learners will not simply open the dictionary and use the alphabet guide at the edge of the page or running heads at the top of the page showing the first and the last headword on each page to find words that fit the context. Guidance is necessary for appropriate use of dictionaries. He (ibid) makes out a seven-step dictionary use strategy that includes:

Finding the items the learner is unaware of.

Removing the inflection (if found).

Locating the unknown word in the alphabetical list.

If the unknown word is not found in the main entry, try to find it in the appendix, nearby entries, or look up parts of the word.

If there are various senses or homographic entries, reduce them by elimination.

Read the definition and try to associate it into the context of the unfamiliar word.

If more than one sense fits, look at more context clues in the text to facilitate your choice.

Nation (2001) also distinguishes four distinct steps for dictionary use as analysing the context of the unknown word, finding the correct entry, choosing the right sub-entry, and applying the meaning to the original context in order to decide if the search was effective.

Moreover, Thornbury (2002) suggests a list of basic skills needed for successful dictionary use. It includes recognising features of dictionary design, understanding the coding and abbreviations used in the entries, discriminating between the different meanings of a word, cross-checking translation equivalents given in bilingual dictionaries, using synonyms, antonyms and other information to find the best word for the item.

All these steps entail individual skills, such as recognizing word classes and inflected forms, alphabetical order, and understanding the symbols and layout conventions of the dictionary. So, learners are compelled to have full understanding of what dictionaries seek to offer and how they do so (Nation, 2001).

\section{Training Language Learners in Dictionary Use:}

Learner autonomy has always been regarded essential in EFL teaching for many years. Researchers emphasized on the significance of teaching learners strategies that facilitate independent vocabulary learning (Sökmen 1997). Thornbury (2002), for example, regards dictionary use as a way of encouraging learners' autonomy, as it offers the learner the opportunity to learn vocabulary outside the classroom. 
Despite the significance of dictionaries in encouraging independent learning, dictionary training is still neglected. As Hartmann (1999) puts it: "Throughout and beyond the English-speaking world, dictionaries (especially EFL learners' dictionaries) are 'big business', but the skills required of their users are still underdeveloped" (p.14).

Bilash, Gregoret, \& Loewen, (1999) maintain that "If we do not teach students how to use the dictionary, it is unlikely that they will demand that they be taught, since, while teachers do not believe that students have adequate dictionary skills, students believe that they do" (p.4).

\section{II -The Learner Questionnaire:}

This questionnaire survey is designed to uncover students' ownership of dictionaries, monolingual English dictionary use, difficulties of dictionary use, and dictionary instruction among students at the University of Frères Mentouri Constantine 1 .

\section{Population and Sampling:}

The sample consists of 80 second year students of English at the department of Letters and English language at the University of Frères Mentouri Constantine 1. The participants' English learning experience is homogeneous in general. They had at least 09 years of experience in studying English. They are both males and females (males 10 and females 70) and do not differ in terms of age very much. The reason for selecting this population was mainly easy accessibility.

\section{Results and Discussion:}

The return rate of the questionnaires was $100 \%$. So, the total number of questionnaire copies was 80 .Then, the percentages were calculated. After the analysis of the results of our questionnaire, we got a general profile of students' dictionary ownership, use, skills, problems, and training.

Vocabulary development is considered a big challenge for learners and academic success. Likewise, Questionnaire data indicated that most of the participants (96.52\%) appear to consider vocabulary an important aspect in language learning. They believed that a rich vocabulary has a direct, positive impact on their learning and life in general. Participants in this study were aware of the fact that vocabulary learning is a complex task. $71.25 \%$ of the respondents reported that English vocabulary is difficult to learn. They stressed some difficulties associated with recalling and using words as well as words combinations.

Dictionaries were considered a helpful strategy to learn vocabulary by most students. The participants considered the dictionary one of the most valuable sources of input for learning vocabulary. They considered dictionaries a good resource for decoding, encoding, and learning purposes.

$88.75 \%$ of the students owned dictionaries. Monolingual dictionary ownership exceeded other types of dictionaries. $68.75 \%$ of the students owned monolingual dictionaries, compared to $50 \%$ of bilingual dictionary owners. The bilingualized dictionaries were owned by only a small proportion of learners $(6.25 \%)$. This is shown in the table 01 below. The results also showed little interest in special dictionaries $(12.5 \%)$ and a high ownership of electronic dictionaries. Most of the participants $(50 \%)$ also reported that they used their monolingual English dictionaries most frequently though the preference for bilingual dictionary use by all EFL dictionary users has been repeatedly confirmed in the previous studies of dictionary use. 


\begin{tabular}{|l|l|l|}
\hline & Number & Percentage \\
\hline Monolingual & 55 & $68.75 \%$ \\
\hline Bilingual & 40 & $50 \%$ \\
\hline Bilingualized & 5 & $6.25 \%$ \\
\hline Electronic & 54 & $67.5 \%$ \\
\hline Specialised & 10 & $12.5 \%$ \\
\hline Others & 00 & $00 \%$ \\
\hline
\end{tabular}

Table 01: Type(s) of Dictionaries Owned by Students

To a large extent dictionary use depends on the tasks students use dictionaries for. The nature of the study and the level of the participants seem to be the main reasons for these results. That is why, Laufer \& Melamed (1994) state that at lower levels, bilingual dictionaries serve as the main entrance to the foreign language; monolingual dictionaries, on the other hand, are particularly indicated for intermediate or advanced learners. At lower levels, bilingual dictionaries are especially useful for production and comprehension; at intermediate levels, bilingual dictionaries are more efficient for production, whereas monolingual ones are more useful for comprehension; and at advanced levels, monolingual dictionaries tend to be the most efficient both in terms of production and comprehension.

In recent years, a lot of technological developments appeared and spread around. The invention of electronic dictionaries has taken place in the operational processes of teaching and learning in ESL/EFL. Students find them very tempting and valued the ease of using them. The results showing that electronic dictionaries are popular among students were not surprising, since electronic dictionaries are easily and quickly accessed as they are nowadays available on students' electronic devices as mobile phones, laptops, and ipods which can encourage dictionary use and hence develop students vocabulary knowledge.

Habitually, the dictionary is consulted by students rather than read. The learners' aim is generally to elucidate specific information as fast as possible, such as one word's pronunciations, spellings, usage, and so on. The Findings of the questionnaire, as shown in table 02 , revealed that the most common use of a dictionary was to find the meaning of words $(56.25 \%)$. The results also show an interest among the participants in spelling (22. 5\%) and pronunciation $(11.25 \%)$. The other types of dictionary information received less importance as grammar (2.5\%), usage (1.25\%), collocations $(1.25 \%)$, and etymology (1.25\%). Frequency was not looked at all. Likewise $00 \%$ percent of the subjects consulted the front matter and the appendices.

\begin{tabular}{|l|l|l|}
\hline & Number & Percentage \\
\hline Meaning & 45 & $56.25 \%$ \\
\hline Spelling & 18 & $22.5 \%$ \\
\hline Pronunciation & 9 & $11.25 \%$ \\
\hline Grammar & 2 & $2.5 \%$ \\
\hline Usage & 1 & $1.25 \%$ \\
\hline Collocations & 1 & $1.25 \%$ \\
\hline Etymology & 1 & $1,25 \%$ \\
\hline Frequency & 00 & $00 \%$ \\
\hline
\end{tabular}




\begin{tabular}{|c|c|c|}
\hline $\begin{array}{l}\text { Introduction } \quad \text { and } \\
\text { Appendices }\end{array}$ & 00 & $00 \%$ \\
\hline Others & 6 & $7.5 \%$ \\
\hline
\end{tabular}

Table 02: Students' Reference Needs

These results are similar to those of previous researches on dictionary use, which showed users' excessive preoccupation with meaning (Hartmann, 1999). It is believed that the participants consult dictionaries most frequently for the meanings of words as they consider the most important function of dictionaries is to provide word meanings. That is why, they give low priority to other aspects as pronunciation, grammatical information, usage, collocations and etymology of words.

These results suggest that students perception of dictionaries as a language learning tool is very restricted. Participants mostly consult their dictionaries because they want to know words' meanings though there are other important reasons for consulting monolingual dictionaries. Aspects like spelling, pronunciation, grammar, collocation, idiomatic expression, and words' use are generally ignored. These results can be a consequence of some methods of vocabulary teaching as the grammar translation which is widely practiced by teachers especially at early stages. Such methods can influence students to focus on meaning more than the other aspects of word knowledge.

$00 \%$ of the participants searched for frequency information though a fundamental fact about a word is how common it is. This information is particularly valuable for language learners, as it immediately indicates how important it is to learn a word. Scholfield (1997) indicates that since students may encounter numerous unknown words in extensive reading, many of which will be quite rare, it is very useful to have a guide to what to skip.

It is also worth noting that no participant reported consulting dictionary' front matter and appendices in spite of the valuable information they contain. The front matter and the appendices of the dictionary include many types of information that are worth reading and save time and space. They include useful information such as the guide to the use of the dictionary, list of phrasal verbs, usage, phonological and encyclopedic information. In addition, much work is spent to compose the front matter and the appendices of good dictionaries. That is why there is a need to encourage learners from an early stage to refer to the introductory and back pages. Kirkness' (2004) claims that "this material is undoubtedly useful, but it is unlikely that learners will consult it, let alone use it systematically, unless teachers explicitly refer to it" (p.300). Students may benefit from getting more information if they knew what exists in their dictionaries and if they are trained in consulting all information in their dictionaries.

Though the majority of the students found themselves effective dictionary user $(62.5 \%)$, when asked about the difficulties they encounter when using the dictionary, the participants reported many problems as illustrated in table 3 . The quality of the information the dictionary provides was generally reported to be the most common problem for most of the students, followed by the lack of the information. Only some students $(8.75 \%)$ blamed their poor skills in dictionary use for their difficulties. So, most students experience some kinds of difficulty while using their dictionaries. These results may give rise to possible points of focus in dictionary training.

\begin{tabular}{|l|c|c|}
\hline & Number & Percentage \\
\hline No information & 31 & $38.75 \%$ \\
\hline
\end{tabular}




\begin{tabular}{|l|c|c|}
\hline $\begin{array}{l}\text { Incomplete and incomprehensive } \\
\text { information }\end{array}$ & 34 & $42.5 \%$ \\
\hline Poor reference skills & 7 & $8.75 \%$ \\
\hline No difficulty & 5 & $6.25 \%$ \\
\hline Others & 3 & $3.75 \%$ \\
\hline
\end{tabular}

Table 03: Students' Sources of Dictionary Use Problems

Given the fact that dictionaries are usually considered familiar tools, students assume that they know how to use a dictionary even if that is not always the case. Despite $67.5 \%$ of the participants in that questionnaire answered that they do not need instruction on how to use their dictionaries, and $60 \%$ of the subjects answered that they have received only little instruction on how to use their dictionaries, dictionary use is considered a complex activity. According to Atkins (1985, p. 23) a dictionary "is not a front-line pedagogical instrument in the same way as a course book, language-lab tape or even a grammar book and learners do not a dictionary and proceed to learn the language from cold". So, students need to be taught explicitly how to use them.

\section{III-- Conclusion:}

This paper mainly investigated English Monolingual Dictionary use among second year students of University of Constantine 1 trough a questionnaire. The purpose of the learner questionnaire was to establish an understanding of students' dictionary ownership, their monolingual dictionary use, difficulties of dictionary use, and dictionary instruction. The results show that monolingual and electronic dictionaries are the most used types of dictionaries. However students do not take advantage of the riches found in their dictionaries. Therefore, teachers have to equip students with the necessary reference skills which in turn will have a positive influence on students' dictionary use.

\section{References:}

[1]. Atkins, B. T. S. (1985). Mononolingual and bilingual learners' dictionaries: a comparison. In R. Ilson (Ed.), Dictionaries, lexicography and Language Learning, ELT documents 120 (pp. 15-24). Oxford: Pergamon Press.

[2]. Atkins, B. T. S., \& Varantola, K. (1997). Monitoring dictionary use. International Journal of Lexicography, 10(1), 1-45.

[3]. Baxter, J. (1980). The dictionary and vocabulary behavior: a single word or a handful?. TESOL Quarterly, 14(3), 325-336.

[4]. Béjoint, H. (2000). Modern lexicography: an introduction. Oxford : Oxford Oxford University Press.

[5]. Bilash, O., William, S., Gregoret, C., \& Loewen, B. (1999). Using classroom dictionaries in second-language classrooms. Mosaic: A Journal for Language Teachers, 6(2), 3-9.

[6]. Cowie, A.P., (1981). The treatment of collocations and idioms in learner's dictionaries. Applied Linguistics 2(3): 223-235.

[7]. Cowie, A.P. (1999). English Dictionaries for Foreign Learners: a History. Oxford: Clarendon Press.

[8]. Fan, M. Y. (2003). Frequency of use, perceived usefulness, and actual usefulness of vocabulary learning strategies: A study of Hong Kong learners. The Modern Language Journal, 87 (2), 222-241.

[9]. Garcia B., "The methodological, linguistic and semiological Bases for the elaboration of a written form of LSF (French Sign Language)", C. Vettori (ed). Proceedings of the Second Workshop on the Representation and 
Processing of Sign Languages : Lexicographic Matters and Didactic Scenarios, 5th International Conference on Language Resources and Evaluation - LREC-2006. ILC-CNR, Gênes, Italie.

[10]. Hartmann, R. R. K. (Ed.). (1999). Sub-Project 9:Dictionaries Dictionaries in Language Learning Recommendations, National Reports And Thematic Reports From The TNP Sub-Project 9: Dictionaries. Berlin: Freie Universität.

[11]. Heuberger, R. (2000): Monolingual Dictionaries for Foreign Learners of English: A Constructive Evaluation of the State-of-the-art Reference Works in Book Form and on CD-ROM. Wien: Wilhelm Braumüller.

[12]. Hulstijn, J. H. \& Atkins, B. T. S. (1998). Empirical Research on Dictionary Use in Foreign- Language Learning: Survey and Discussion. In: Atkins, B. T. S. (ed.), 7-19.

[13]. Jakubowski, M. (2001). The use of dictionaries by high school learners: The place of the monolingual and bilingual dictionary in the learning process. (Master thesis).

[14]. Kirkness, A (2004) Lexicography', in A Davies \& C Elder (eds), The handbook of applied linguistics, Blackwood Publishing Ltd, Oxford, pp. 5481.

[15]. Koren S. (1997). Quality versus convenience: comparison of modern, dictionaries from the researcher's, teacher's and learner's points of view. TESL-EJ 2(3).p1-16.

[16]. Laufer, B. (1995). A case for semi-bilingual dictionary for production purposes. Kernerman Dictionary News 3.

[17]. Laufer, B. \& Hadar, L. (1997). Assessing the Effectiveness of Monolingual, Bilingual, and, Bilingualised" Dictionaries in the Comprehension and Production of New Words. The Modern Language Journal 81(2): 189-196.

[18]. Laufer \& Melamed, L. (1994). Monolingual, bilingual and bilingualised dictionaries: which are more effective, for what and for whom? In: Martin, W. (ed.), EURALEX 94 Proceedings . Amsterdam: Free University, 565-576.

[19]. Lew, R. (2002). A Study in the Use of Bilingual and Monolingual Dictionaries by Polish Learners of English: A Preliminary Report. In: Braasch, A. \& Povlsen, C. (eds.), Proceedings of the Tenth EURALEX International Congress, EURALEX 2002. Vol. 2. Copenhagen: Center for Sprogteknologi (CST) 759-764.

[20]. Nation, P. (2001). Learning vocabulary in another language. Cambridge: Cambridge University Press.

[21]. Nesi, H. (1999). The specification of dictionary reference skills in higher education. In: Hartmann, R. R. K. (ed.), Thematic Network Project in the area of Languages. Sub- project 9: Dictionaries. Dictionaries in Language Learning .

[22]. Nesi, H. (2000). The Use and Abuse of EFL Dictionaries. Tübingen: Niemeyer.

[23]. Nesi, H. \& Haill, R. (2002). A Study of Dictionary Use by International Students at a British University. International Journal of Lexicography 15(4): 277-305.

[24]. Nesi, H. \& Meara, P. (1994). Patterns of misrepresentation in the productive use of EFL dictionary definitions. System 22(1): 1-15.

[25]. Neubach, A. \& Cohen, A. D. (1988). Processing strategies and problems encountered in the use of dictionaries. Dictionaries 10: 1-19. 
[26]. Papanikolaou, E. (2003). Dictionary use in a reading task among Greek junior secondary school students of English: a multi-method approach. (Doctoral thesis).

[27]. Pujol, D., Corrius, M., Masnou, J., (2006). Print deferred bilingualised dictionaries and their implications for effective language learning: A new approach to pedagogical lexicography. International Journal of Lexicography 19 (2), 197-

[28]. Rundell, M. (1999). Dictionary use in production. International Journal of Lexicography 12(1): 35-53.

[29]. Schmitt, N. \& McCarthy, M. (Eds.). (1997). Vocabulary: Description, Acquisition and Pedagogy. Cambridge: Cambridge University Press.

[30]. Scholfield, P. (1997). Vocabulary reference works in foreign language learning. In N. Schmitt \& M. McCarthy (Eds.), Vocabulary: description, acquisition, and pedagogy (pp. 279-302).

[31]. Strevens, P. (1987). The effectiveness of learners' dictionaries. In R. Burchfield (Ed.), Studies in lexicography (pp. 76-93). Oxford: Oxford University Press.

[32]. Summers, D. (1988). The role of dictionaries in language learning. In: In: Carter, R. \& McCarthy, M. (eds.), Vocabulary and Language Teaching . London: Longman, 111- 125.

[33]. Swanepoel, P. (2003). Dictionary Typologies: A Pragmatic Approach. In Sterkenburg, P V A. (ed). Practical Guide to lexicography (terminology and lexicography research and practice), 6th Ed. Philadelphia, PA: John Benjamins Publishing Co. p. 44-45.

[34]. Tarp, S. (2009). Reflexions on lexicographical user research. Lexikos 19: 1-22.

[35]. Thornbury, S. (2002). How to teach Vocabulary. London \& New York: Longman.

[36]. Tickoo, M. L. (1989). Which Dictionaries and Why? Exploring Some Options. In: Tickoo, M. L. (ed.), Learners' Dictionaries. State of the Art. Singapore: SEAMEO Regional Language Centre, 184-203.

[37]. Tomaszczyk, J. (1987). FL Learner's communication failure: implications for pedagogical lexicography. In: Cowie, A. P. (ed.), 136-145.

[38]. Tono, Y. (1984). On the Dictionary User's Reference Skill. (B.ED. thesis).

[39]. Wingate, U. (2002). The Effectiveness of Different Learner Dictionaries. An Investigation into the Use of Dictionaries for Reading Comprehension by Intermediate Learners of German . Tübingen: Niemeyer.

[40]. Winkler, B. (2001). English learners' dictionaries on CD-ROM as reference and language learning tools. ReCALL 13(2): 191-205.

[41]. Wright, J. (1998). Dictionaries. Resource Books for Teachers. Oxford: Oxford University Press. 